\title{
Genetic Diversity of Colletotrichum spp. Causing Strawberry Anthracnose in Zhejiang, China
}

\author{
X. Y. Chen, ${ }^{1}$ D. J. Dai, ${ }^{1,2}$ S. F. Zhao, ${ }^{3}$ Y. Shen, ${ }^{2}$ H. D. Wang,,${ }^{1,2}$ and C. Q. Zhang ${ }^{1, \dagger}$ \\ ${ }^{1}$ Department of Plant Pathology, Zhejiang Agriculture and Forest University, Hangzhou 311300, China \\ ${ }^{2}$ Institute for the Control of Agrochemicals of Zhejiang Province, Hangzhou 310020, China \\ ${ }^{3}$ Station of Plant Protection of Jiande City, Zhejiang Province, Jiande 311600, China
}

\begin{abstract}
Anthracnose is a serious fungal disease that primarily infects strawberry roots and stolons during development. Here, 91 isolates from different areas of Zhejiang province, China, were collected. Morphological characteristics were analyzed, and a phylogenetic analysis based on multiple genes (actin, internal transcribed spacer, calmodulin, glyceraldehyde-3-phosphate dehydrogenase, and chitin synthase) was performed. We found that all of the Colletotrichum species causing strawberry anthracnose belonged to the Colletotrichum gloeosporioides complex. Among them, we identified 48 isolates of $C$. fructicola, 21 isolates of $C$. siamense, 13 isolates of $C$. gloeosporioides, and 9 isolates of $C$. aenigma. $C$. siamense was distributed in the central and eastern regions of Zhejiang province (Hangzhou, Jinhua, Shaoxing,

Ningbo, and Taizhou). This is the first report of $C$. siamense causing strawberry anthracnose in Zhejiang province. C. fructicola was the most dominant species causing strawberry anthracnose in Zhejiang province. We identified the four species causing strawberry anthracnose in Zhejiang province, which will improve our understanding of the strawberry anthracnose epidemic and will benefit the development of future control measures.

Keywords: Colletotrichum fructicola, Colletotrichum gloeosporioides complex, Colletotrichum siamense, fruit, fungi, morphological characterization, pathogen diversity, phylogenetic analysis, small fruits, strawberry anthracnose
\end{abstract}

Strawberries (Fragaria $\times$ ananassa), which are native to South America, are widely cultivated in China (Henz et al. 1992). The area devoted to strawberry cultivation increased from 90,100 ha in 1985 to 330,000 ha in 2012; China produces $35.7 \%$ of all strawberries worldwide, and it is the largest producer of strawberries globally (Peng and Peng 2011). Zhejiang province is the one of the top eight strawberry-producing regions in China (Shen 2014).

Strawberry anthracnose is a serious fungal disease that can affect plants at any stage during their lifecycle (Henz et al. 1992). However, plants are most susceptible to strawberry anthracnose at the seedling stage and immediately after planting (Wang et al. 2008). Anthracnose primarily affects strawberry roots, petioles, and stolons, but flowers and fruit can also be infected, leading to severe outbreaks (Mertely and Legard 2004). Symptoms are irregular ulcer-like lesions, reddish brown stolons during the initial stages of stolon development, leaves and petioles with black spindleshaped lesions, wilt, and dead roots (Debode et al. 2009; Freeman and Katan 1997). In Zhejiang, nearly $50 \%$ of all seedling deaths and $>40 \%$ of all production losses in the nursery are attributed to this disease (Xie et al. 2010). During the entire plant growth cycle, strawberry was threatened by anthracnose disease. If environmental conditions are suitable, anthracnose decreased the strawberry yield by $80 \%$. Transplants are believed to be the main source of primary inoculum, but complete epidemiology of Colletotrichum spp. on strawberry in China is unclear.

${ }^{\dagger}$ Corresponding author: C. Q. Zhang; cqzhang@ zafu.edu.cn

Funding: This work was supported by the Key Research and Development Project of Zhejiang Province, China grant No. 2015C02G1320008.

*The $\boldsymbol{e}$-Xtra logo stands for "electronic extra" and indicates that three supplementary figures and one supplementary table are published online.

The author(s) declare no conflict of interest.

Accepted for publication 24 December 2019.

C 2020 The American Phytopathological Society
Colletotrichum spp. often cause anthracnose disease in herbaceous or woody plants in tropical and subtropical regions (Cannon et al. 2012). The genus Colletotrichum is one of the eight plant pathogens worldwide (Dean et al. 2012). Three Colletotrichum species or species complexes have been reported to cause strawberry anthracnose: the Colletotrichum gloeosporioides complex, Colletotrichum fragariae, and the Colletotrichum acutatum complex (Denoyes-Rothan et al. 2003). The C. gloeosporioides complex is found worldwide and has a wide range of hosts, whereas $C$. acutatum and $C$. fragariae both have narrow host ranges (MacKenzie et al. 2008). Although a few $C$. acutatum infections in Chinese strawberries have been reported, the primary species affecting strawberries in China are believed to be $C$. gloeosporioides and C. fragariae (Buddie et al. 1999; Han et al. 2016). The pathogens causing strawberry anthracnose in Hubei province, China, were divided into two groups: the $C$. gloeosporioides species complex (Colletotrichum aenigma, Colletotrichum fructicola, $C$. gloeosporioides, and Colletotrichum murrayae) and the C. acutatum complex (C. acutatum and Colletotrichum nymphaeae). In Florida, Ureña-Padilla et al. (2002) suggested that the pathogen-causing anthracnose on the strawberry root crowns and stolons was $C$. gloeosporioides, whereas the pathogens causing anthracnose on the strawberry fruit were members of the $C$. acutatum complex.

Based on morphological characters and analysis of internal transcribed spacer (ITS) ribosomal DNA, Xie et al. (2010) showed that strawberry anthracnose infections in Zhejiang and Shanghai were caused by $C$. gloeosporioides, C. acutatum, and C. fragariae. However, because this study only analyzed a single region and did not use multiple genes, the results may not be accurate. Indeed, multigene phylogenetic analyses in conjunction with morphological characters have been used to identify many important pathogens (Cai et al. 2009; Damm et al. 2012; Weir et al. 2012). The classification and delimitation of Colletotrichum species have been debated (Weir et al. 2012). Many Colletotrichum isolates have been successfully identified based on multigene phylogenies and morphological characters, indicating that this method is mature and can accurately identify pathogens (Damm et al. 2012). Morphological characters and multigene phylogenies have not been used to identify the Colletotrichum species associated with strawberry anthracnose in China or to determine the distributions of these species. 
The objectives of this study were (i) to use morphological and molecular characters to identify the species causing strawberry anthracnose in Zhejiang province and (ii) to determine the distributions and pathogenicity of Colletotrichum species throughout the region.

\section{Materials and Methods}

Source and collection of fungal isolates. Zhejiang province $\left(27^{\circ} 02^{\prime}\right.$ to $31^{\circ} 11^{\prime} \mathrm{N}, 118^{\circ} 01^{\prime}$ to $\left.123^{\circ} 10^{\prime} \mathrm{E}\right)$ is located on the southeast coast of the Yangtze River in southeastern China (He et al. 2013), and it has a humid, subtropical monsoon climate. We collected 234 anthracnose samples from strawberry plants cultivated in Zhejiang province between 2013 and 2017 (Fig. 1). The samples included irregularly shaped lesions from the stem; black, spindle-shaped lesions from the leaves or petioles; reddish brown stolons; or the entire plant if roots were withered (Supplementary Fig. S1).

Pathogens were isolated from diseased petiole, leaf, stolon, or root tissues. The diseased plant tissues were first cut into $5 \times 5$-mm pieces using sterilized scissors. Excised tissue pieces were rinsed in $75 \%$ ethanol solution for $30 \mathrm{~s}$, soaked in a $3 \%$ sodium hypochlorite solution (active chlorine: $6.8 \%$ ) for $3 \mathrm{~min}$, rinsed three times with sterile distilled water, and then, dried on sterile filter paper. After it was dried, each sample was placed on a plate containing potato dextrose agar (PDA) medium supplemented with a final concentration of $50 \mathrm{mg} / \mathrm{ml}$ of kanamycin sulfate and streptomycin sulfate to inhibit bacterial growth. The plate was incubated in an incubator at $25^{\circ} \mathrm{C}$ in darkness for 3 to 5 days. Hyphal growth was aseptically transferred to a new PDA plate (Cai et al. 2009; Phoulivong et al. 2010). Anthracnose isolates were identified and selected based on the morphological characteristics of each species. Isolates were maintained on PDA slants at $4^{\circ} \mathrm{C}$.

DNA extraction and PCR. When about $67 \%$ of the PDA plate (90 $\mathrm{mm}$ ) was covered by mycelia, the hyphae were scraped off with sterile slides. DNA was extracted from the hyphae using a fungal genomic DNA rapid extraction kit (B518229-0100; Sangon Biotech). DNA extracted from each isolate was stored at $-20^{\circ} \mathrm{C}$. The target genes amplified in this study were actin (ACT), calmodulin (CAL), chitin synthase (CHS-1), glyceraldehyde-3-phosphate dehydrogenase (GAPDH), and the ITS. The corresponding primers used for PCR amplification are shown in Table 1.

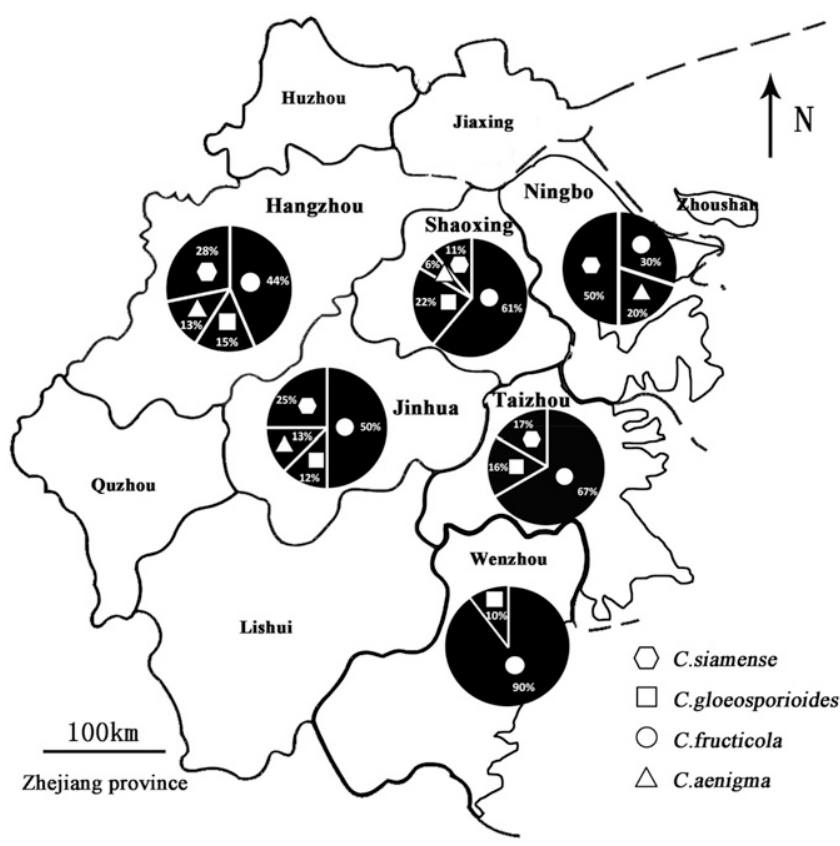

Fig. 1. Distribution of Colletotrichum spp. associated with strawberry anthracnose in Zhejiang province, China. For each region, the percentage occurrences of the four Colletotrichum species are given: Hangzhou $(n=43)$, Shaoxing $(n=18)$, Ningbo $(n=10)$, Taizhou $(n=6)$, Jinhua $(n=4)$, and Wenzhou $(n=10)$. C. aenigma, Colletotrichum aenigma; C. fructicola, Colletotrichum fructicola; $C$. gloeosporioides, Colletotrichum gloeosporioides; $\mathrm{C}$. siamense, Colletotrichum siamense.
The PCRs were performed in an Applied Biosystems Veriti Thermal Cycler in a total volume of $50 \mu \mathrm{l}$. The PCR mixtures contained $31.6 \mu \mathrm{l}$ of UV-sterilized ultrafiltered water, $5 \mu \mathrm{l}$ of $10 \times$ PCR buffer (with $20 \mathrm{mM} \mathrm{MgCl} 2$ ), $5 \mu \mathrm{l}$ of dNTPs (each $20 \mu \mathrm{M}$ ), $2 \mu \mathrm{l}$ of each primer $(10 \mu \mathrm{M}), 2 \mu \mathrm{l}$ of abumin from bovine serum (BSA), $2 \mu \mathrm{l}$ of genomic DNA, and $0.4 \mu \mathrm{l}(1 \mathrm{U})$ of Roche FastStart Taq DNA Polymerase.

PCRs were performed in a thermal cycler (PTC-100TM Peltier Thermal Cycler). The parameter for GAPDH is as follows: denaturation at $94^{\circ} \mathrm{C}$ for $5 \mathrm{~min}$ followed by 30 cycles of $94^{\circ} \mathrm{C}$ for $30 \mathrm{~s}, 60^{\circ} \mathrm{C}$ for $30 \mathrm{~s}$, and $72^{\circ} \mathrm{C}$ for $0.5 \mathrm{~min}$ and a final cycle at $72^{\circ} \mathrm{C}$ for $10 \mathrm{~min}$. The parameter for ITS is as follows: $94^{\circ} \mathrm{C}$ for $5 \mathrm{~min}$ followed by 30 cycles of $94^{\circ} \mathrm{C}$ for $1 \mathrm{~min}, 52^{\circ} \mathrm{C}$ for $30 \mathrm{~s}$, and $72^{\circ} \mathrm{C}$ for $40 \mathrm{~s}$ and a final step at $72^{\circ} \mathrm{C}$ for $10 \mathrm{~min}$. The parameter for CAL is as follows: $94^{\circ} \mathrm{C}$ for $5 \mathrm{~min}$ followed by 30 cycles of $94^{\circ} \mathrm{C}$ for $1 \mathrm{~min}, 55^{\circ} \mathrm{C}$ for $45 \mathrm{~s}$, and $72^{\circ} \mathrm{C}$ for $40 \mathrm{~s}$ and a final step at $72^{\circ} \mathrm{C}$ for $10 \mathrm{~min}$. The parameter for the ACT and CHS-1 is as follows: denaturation at $94^{\circ} \mathrm{C}$ for $4 \mathrm{~min}$ followed by 30 cycles of $94^{\circ} \mathrm{C}$ for $30 \mathrm{~s}, 58^{\circ} \mathrm{C}$ for $30 \mathrm{~s}$, and $72^{\circ} \mathrm{C}$ for $1 \mathrm{~min}$ and a final cycle of $10 \mathrm{~min}$ at $72^{\circ} \mathrm{C}$ (Weir et al. 2012).

PCR products were assessed using electrophoresis: $50 \mu$ of each amplicon was run on a $1 \%$ agarose gel stained with ethidium bromide in $1 \%$ Tris-acetate EDTA buffer for $30 \mathrm{~min}$ and then, photographed under UV light (Han et al. 2016). Gels were sent to Kingsley (Nanjing, China) for sequencing.

All sequences were grouped by gene and aligned using DNAMAN v. 7.0. Sequences with single-nucleotide polymorphisms were amplified and sequenced three times to ensure that the observed polymorphisms were not because of sequencing errors.

Molecular identification and phylogenetic analyses. Sequences homologous to the ACT, CAL, CHS-1, GAPDH, and ITS gene sequences from the isolates were downloaded from GenBank. Colletotrichum boninense (International Collection of Microorganisms from Plants [ICMP] 17904) was used as the outgroup (Hyde et al. 2014; Weir et al. 2012). All sequences were aligned using Clustal X 2.0.10 (Larkin et al. 2007). Gene sequences were compared and corrected using the "W" function in MEGA 5.0 (Tamura et al. 2011). Gene sequences were concatenated. Modeltest3.7.win, Win-paup4b10-console, and Mrmodeltest2 (Nylander 2004) as implemented in the MrMTgui were used to estimate the best model of nucleotide substitution (Vaidya et al. 2011). Bayesian inference (BI) phylogenies were constructed using Mr. Bayers v. 3.1.2 (Ronquist and Huelsenbeck 2003). Six simultaneous Markov chains were run for 1,000,000 generations each, and trees were sampled every 100th generation. The first 2,000 trees, representing the burn-in phase of the analyses, were discarded, and the remaining 8,000 trees were used to calculate posterior probabilities in the majority rule consensus tree. Phylogenetic trees were drawn using Treeview (Page 1996). The alignments and trees have been deposited in TreeBASE. The fungal isolates used in this study are listed in Supplementary Table S1.

Morphological and cultural characterization. Morphological and cultural characterizations were performed for all of the 91 isolates according to the methods described by Cai et al. (2009). Mycelia plugs $(5.0 \mathrm{~mm}$ in diameter) from the edge of an actively growing 5-day-old colony of each tested isolate on PDA were transferred to PDA plates, and they were incubated at $28^{\circ} \mathrm{C}$ under a mixture of white and near-UV fluorescent light sources with a 12-h light/12-h dark cycle. The experiment was designed as a randomized complete block, with three replicates of each isolate. Colony color, conidial dimensions, and morphology were assessed using previous described methods (Cai et al. 2009; Peng et al. 2013; Weir et al. 2012). Conidial suspensions of each species were prepared in lactic acid from conidial masses grown on PDA. The shape and color of the conidia were observed, and the sizes of 50 conidia from each isolate were measured at 400× magnification under a light microscope (Carl Zeiss Microscopy $\mathrm{GmbH}$ ).

Pathogenicity testing. Ninety-one isolates were cultured on PDA medium for 5 days at $25^{\circ} \mathrm{C}$. Samples of these isolates were collected from the colony edge using a 5-mm punch. The mycelial surface of sample was placed in the center of an oat medium plate and cultured at $25^{\circ} \mathrm{C}$ for 5 days. The hyphae on the surface of the resulting colony were scraped off and grown at $25^{\circ} \mathrm{C}$ under a mixture of white and 
near-UV fluorescent light sources with a 12-h light/12-h dark cycle for 10 to 15 days (de los Santos García de Paredes and Romero Muñoz 2002). After the production of a large number of conidial heaps, spore suspensions were collected in $1.5-\mathrm{ml}$ centrifuge tubes using sterilized toothpicks. Spore suspensions were adjusted to $2.0 \times 10^{6}$ conidia per milliliter using a hemocytometer.

Six-week-old leaves of strawberry healthy plants (variety of Zhang Ji) that had not been treated with any chemicals were used for inoculations. Both wounded leaves, which were scratched but not pierced with a sterilized insect needle, and nonwounded leaves were adopted to assess the pathogenicity and evaluate the effect of wounds on the infection. Each leaf was inoculated by drop of $10-\mu l$ spore suspensions, and the negative control was inoculated with sterile water. Additionally, nine plants were inoculated for each isolate. Then, plants were cultured in a greenhouse at $25 \pm 5^{\circ} \mathrm{C}$ for 7 days under a light/dark cycle. Disease was assessed after 7 days by measuring the diameter of the disease lesion (Han et al. 2016). We calculated the disease incidence rate as the number diameter of the disease lesion (Han et al. 2016). Data from the pathogenicity test were subjected to oneway analysis of variance using the software IBM SPSS Statistics v22 to determine the significance of differences. Means for different species from the pathogenicity test were separated using the least significance difference test at $P=0.05$ level.

\section{Results}

Isolates of Colletotrichum spp. from strawberries in Zhejiang. Between 2013 and 2017, 234 samples with typical anthracnose symptoms (Supplementary Fig. S1) were collected in Hangzhou, Ningbo, Taizhou, Shaoxing, and Wenzhou of Zhejiang province, China. From these samples, 91 isolates causing anthracnose were isolated. The distributions of the isolates across the region sampled are shown in Figure 1.

Molecular identification and phylogenetic analyses. The ACT, CAL, CHS-1, GAPDH, and ITS genes from all isolates were successfully amplified and sequenced. All isolates were identified as members of the $C$. gloeosporioides species complex. BI was performed on the haplotypes belonging to the $C$. gloeosporioides species complex based on the concatenated ACT, CHS-1, CAL, GAPDH, and ITS sequences. The concatenated alignment included 2,486 characters. The boundaries of the loci used in the alignment were as follows: ACT: 1 to 311 ; CAL: 312 to 1,189 ; CHS: 1,190 to 1,496 ; GAPDH: 1,497 to 1,804; and ITS: 1,805 to 2,486 .

The tested 91 isolates fell into four clades. BI values indicated that 48 isolates clustered with $C$. fructicola, 21 isolates clustered with Colletotrichum siamense, 13 isolates clustered with C. gloeosporioides, and 9 isolates clustered with C. aenigma (Fig. 2). C. fructicola was most frequently isolated, identified in $53 \%$ of all samples, and BI values of 1.0 between 48 tested isolates. The BI values between tested isolates and $C$. fructicola ICMP 17921*, ICMP 18646*, and ICMP $18581^{*}$ were $1.0,0.92$, and 0.92 , respectively. C. siamense $(23 \%$ of all samples) was distributed mainly in the central and eastern regions of Zhejiang province (Hangzhou, Jinhua, Shaoxing, Ningbo, and Taizhou). Nine isolates had BI values of 0.5 with $C$. siamense
ICMP $18642 *$, whereas the other four and eight isolates both had BI values of 0.53 with $C$. siamense ICMP $19118^{*}$ and $C$. siamense ICMP $18578^{*}$, respectively. The third species, identified as $C$. gloeosporioides, accounted for $14 \%$ of all samples with BI values of 1 , and it was primarily distributed in the central part of Zhejiang province (Hangzhou, Jinhua, Shaoxing, and Ningbo). The fourth species (10\%), C. aenigma, which was found in the central part of Zhejiang province as, had BI values of 0.89 with $C$. aenigma ICMP $18608^{*}$ (Figs. 1 and 2).

Morphological characters. The morphologies of the colonies of the four species grown on PDA media did not differ substantially. $C$. fructicola produced white colonies with irregular gray edges, and colonies were black on the back of PDA plates. The orange conidia were cylindrical with blunt or pointed ends, and attached cells were single or scattered. Most conidia were spherical, cylindrical, or spindle shaped, and very few were irregular. A small number of conidia produced two nearly circular attached cells (Fig. 3). The $C$. siamense colony was fluffy, with gray-white edges. The colony was neatly arranged, with yellow margins in the middle of the back of PDA plates. Conidia were straight, cylindrical, colorless, and smooth, with blunt ends. Spores attached to cells were brown, oval, or spindle shaped, with complete edges. A few irregularly shaped spores were observed (Fig. 4). The C. gloeosporioides colony was gray in the middle with white edges, and the back of the colony was black to gray with white edges. The conidial heaps were orange, cylindrical, and blunt at both ends or slightly pointed at one end (Fig. 5). Attached cells were single or scattered, and most were spherical or elliptical, with a few irregular cells. The aerial hyphae of $C$. aenigma were sparse, light gray to white, and flocculent. The colony was light white on the back, with a gray-green center. Conidia heaps were rare. The conidia were stick like, with one end obtusely rounded or with both ends slightly rounded. Most conidia had oil balls. Conidia were singly or loosely distributed, dark brown, and ovate or irregularly shaped. Some conidia were clover shaped (Fig. 6). Mycelial growth rates, attached cells, and conidia sizes in details are described in Table 2.

Pathogenicity assays. All isolates of each species showed stronger pathogenicity on wounded leaves than on nonwounded leaves (Table 2). For example, all isolates of $C$. fructicola had mean disease incidence (percentage) rates of $79.9 \pm 0.7$ and $22.2 \pm 0.7$ and lesion diameters of 20.5 and $17.0 \mathrm{~mm}$ on wounded and nonwounded leaves, respectively. Meanwhile, significant difference $(P=0.05)$ was observed in lesion diameter but not in disease incidence between four species on wounded leaves. On nonwounded leaves, significant difference $(P=0.05)$ was observed in both lesion diameter and disease incidence between species, and $C$. fructicola had higher pathogenicity.

Significant difference existed between and within species (Table 2). In Supplementary Figure S2, one isolate with the strongest pathogenic ability within each species was presented: C. fructicola (HJD-49), C. siamense (HJD4-7), C. gloeosporioides (GT-10), and C. aenigma (nbg-18). HJD-49 (C. fructicola) had strong pathogenicity both on wounded leaves and on nonwounded leaves. Among C. siamense, the first reported species on strawberry in Zhejiang, only a small portion of isolates, such as HJD4-7, caused similar disease on both

Table 1. Primers used in this study with sequences and sources

\begin{tabular}{lllcll}
\hline Gene & Primers & Direction & Length $(\mathbf{b p )}$ & \multicolumn{1}{c}{ Sequence } & Reference \\
\hline ACT $^{\mathrm{z}}$ & ACT-512F & Forward & 399 & ATGTGCAAGGCCGGTTTCGC & Carbone and Kohn (1999) \\
& ACT-783R & Reverse & & TACGAGTCCTTCTGGCCCAT & Carbone and Kohn (1999) \\
CAL & CL1C & Forward & 773 & GAATTCAAGGAGGCCTTCTC & Weir et al. (2012) \\
& CL2C & Reverse & & CTTCTGCATCATGAGCTGGAC & Weir et al. (2012) \\
CHS-1 & CHS-79F & Forward & 779 & TGGGGCAAGGATGCTTGGAAGAAG & Carbone and Kohn (1999) \\
& CHS-354R & Reverse & \multirow{2}{*}{870} & TGGAAGAACCATCTGTGAGAGTTG & Carbone and Kohn (1999) \\
GAPDH & GDF & Forward & & GCCGTCAACGACCCCTTCATTGA & Templeton et al. (1992) \\
& FDR & Reverse & \multirow{2}{*}{593} & GGGTGGAGTCGTACTTGAGCATGT & Templeton et al. (1992) \\
ITS & Its-1F & Forward & & TCCTCCGCTTATTGATATGC & Gardes and Bruns (1993) \\
& Its-4 & Reverse & & White et al. (1990) \\
\hline
\end{tabular}

${ }^{\mathrm{z}}$ ACT, actin; CAL, calmodulin; CHS-1, chitin synthase; GAPDH, glyceraldehyde-3-phosphate dehydrogenase; ITS, internal transcribed spacer. 
wounded leaves and nonwounded leaves, whereas most isolates, such as ZJE-3, had strong pathogenicity on wounded leaves but weak pathogenicity on nonwounded leaves (Supplementary Fig. S3).

\section{Discussion}

This study performed a phylogenetic analysis using a combination of five genes (GAPDH, CAL, CHS-1, ACT, and ITS) (Damm et al. 2012; Weir et al. 2012) and used this phylogeny as well as morphological characters to identify 91 different isolates from samples of strawberry anthracnose collected in six cities in Zhejiang province, China. The species causing strawberry anthracnose were identified as $C$. fructicola, $C$. gloeosporioides, $C$. aenigma, and $C$. siamense. All four of these species belong to the $C$. gloeosporioides species complex. The C. gloeosporioides complex, C. fragariae, and the C. acutatum complex have been previously reported to infect strawberries and cause strawberry anthracnose (Denoyes-Rothan et al. 2003 ). The $C$. gloeosporioides complex includes $>30$ species, including C. gloeosporioides (Cannon et al. 2008; Weir et al. 2012).
This is the first report of $C$. siamense infecting strawberry plants and causing strawberry anthracnose in Zhejiang. We found that $C$. siamense was the second most common species causing strawberry anthracnose in Zhejiang province. $C$. siamense is a synonym of Colletotrichum jasmini-sambac (Wikee et al. 2011) and Colletotrichum hymenocallidis (Yan et al. 2011). Although this species was originally described from coffee plantations in Thailand, it has a wide geographical distribution and host range (Prihastuti et al. 2009). Based on the variability in $C$. siamense morphological characters, it has been suggested that environment conditions might affect mycelial growth ( $\mathrm{Li}$ 2012). Different types of $C$. siamense colonies were observed in this study. The hyphal growth rate was relatively slow under the culture conditions used here. The colonies were generally grayish white, and a conidia pile was easily produced on PDA media. In the inoculation study, pathogenicity differed even within species. The isolates of $C$. siamense have rarely been studied, but our results indicate that future studies of the pathogenesis of these isolates are needed.

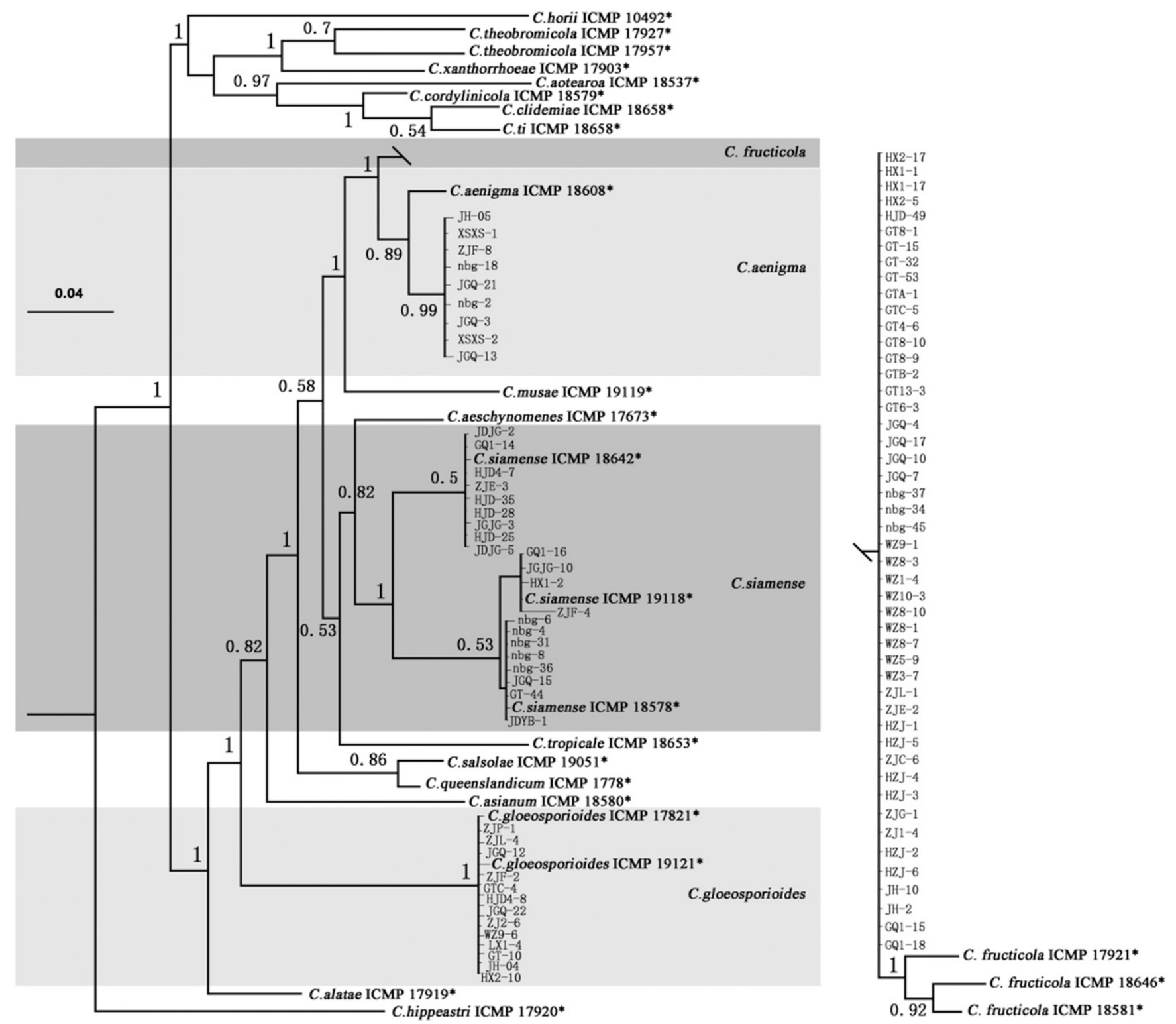

Fig. 2. Phylogeny of 91 isolates in the Colletotrichum gloeosporioides species complex. The tree was constructed based on concatenated actin, internal transcribed spacer, calmodulin, glyceraldehyde-3-phosphate dehydrogenase, and chitin synthase gene sequence; the evolution of each gene was modeled separately. Values next to nodes are Bayesian posterior probability values based on 6,000,000 generations. Colletotrichum hippeastri was used as an outgroup. Ex-type cultures are emphasized in bold and include the taxonomic name as originally described. The scale bar indicates the number of expected changes per site. C. aenigma, Colletotrichum aenigma; C. fructicola, Colletotrichum fructicola; C. gloeosporioides, Colletotrichum gloeosporioides; C. siamense, Colletotrichum siamense. 
C. fructicola was originally reported in Thailand as a pathogen of coffee berries. This isolate grows quickly in hot, humid conditions, and it has a strong sporulation ability (Prihastuti et al. 2009). The species $C$. fructicola, $C$. gloeosporioides, and $C$. aenigma can cause strawberry anthracnose (Han et al. 2016). Here, C. fructicola accounted for $52.7 \%$ of all samples and was observed in all regions sampled, suggesting that this is the dominant species causing strawberry anthracnose in Zhejiang province. It is believed that $C$. fructicola is more pathogenic than $C$. gloeosporioides or $C$. aenigma (Han et al. 2016). Consistent with this, our pathogenicity experiments showed that $C$. fructicola was more pathogenic than $C$. gloeosporioides and $C$. aenigma. A previous study reported that $C$. murrayae was the dominant species causing strawberry anthracnose in Hubei, China, but no isolates of this species were found in this study (Han et al. 2016).

C. gloeosporioides was previously thought to infect many types of fruit, particularly in the tropics (Afanador-Kafuri et al. 2003; Freeman et al. 1998; Sangeetha and Rawal 2007). However, studies have shown that this species is uncommon in the tropics and rarely causes anthracnose in tropical fruits (Phoulivong et al. 2010; Prihastuti et al. 2009; Rojas et al. 2010; Udayanga et al. 2013). In addition, not all isolates of $C$. gloeosporioides were pathogenic to strawberries in greenhouse tests (Mertely and Legard 2004). Here, C. gloeosporioides was present in $14.3 \%$ of all samples, and it was the third most dominant group.
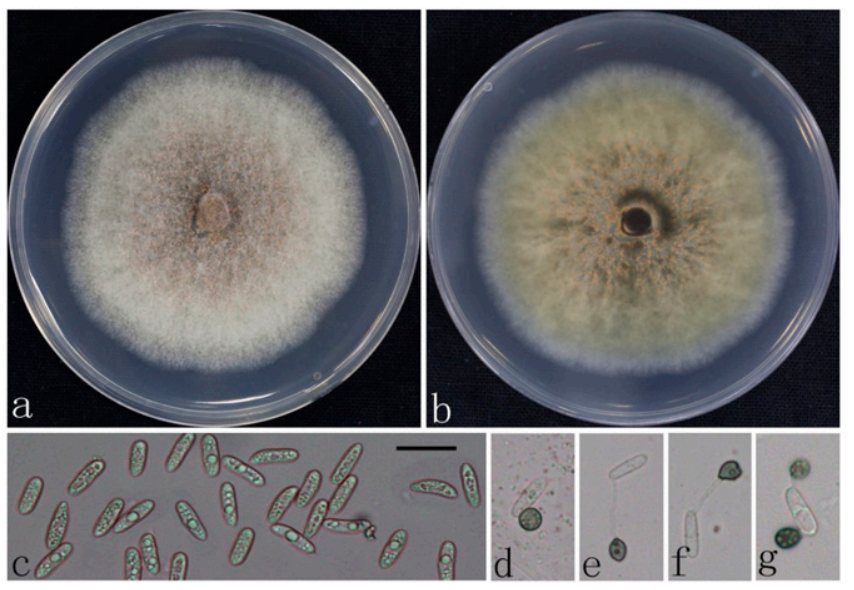

Fig. 3. Colletotrichum fructicola. $\mathbf{a}$ and $\mathbf{b}$, Cultures of HJD-49 on potato dextrose agar; $7-d$ growth from single conidia from above and below. c, Conidia. $d$ to f, Appressoria. Scale bar in $\mathbf{c}=20 \mu \mathrm{m}$ in $\mathbf{c}$ to $\mathrm{f}$.
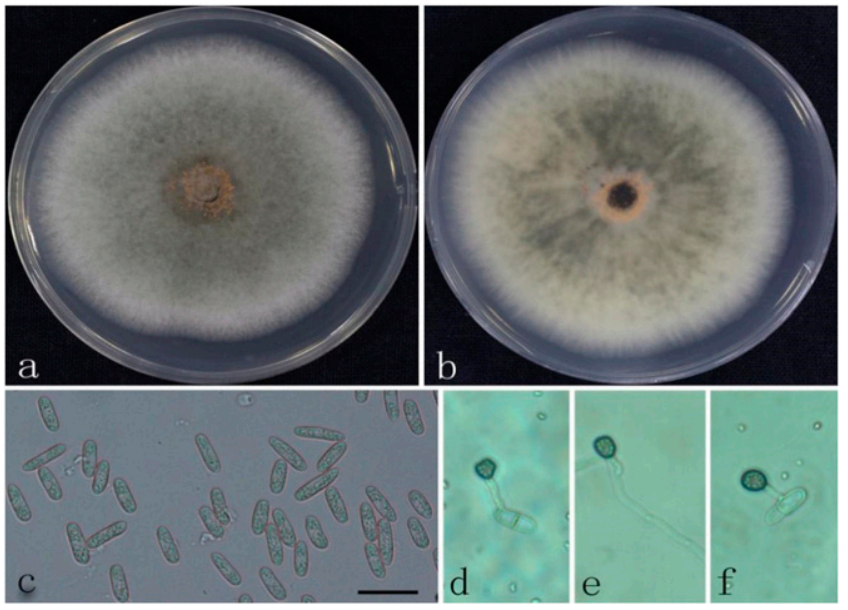

Fig. 4. Colletotrichum siamense. $\mathbf{a}$ and $\mathbf{b}$, Cultures of HJD4-7 on potato dextrose agar; 7-d growth from single conidia from above and below. c, Conidia. $\mathbf{d}$ to f, Appressoria. Scale bar in $\mathbf{c}=20 \mu \mathrm{m}$ in $\mathbf{c}$ to $\mathrm{f}$.
However, we found that the disease index of this species was low, consistent with previous studies (Hu et al. 2014).

C. aenigma was first described by Weir et al. (2012) based on phylogenetic analysis and morphological descriptions. This species primarily infects Pyrus pyrifolia in Japan and Persea americana in Israel (Weir et al. 2012), but it has been reported on grapes and a wide range of hosts (Yan et al. 2011). It is less virulent to strawberries, and it does not resist high temperatures (Han et al. 2016). The distribution of $C$. aenigma on strawberries in Zhejiang province is relatively sparse (Yan et al. 2011). The description of Colletotrichum annigma might be useful for the classification of the C. gloeosporioides complex, and the characteristics of this species require further study.

Strawberry anthracnose was previously thought to be caused by a complex of $C$. gloeosporioides species, $C$. acutatum species, and $C$. fragariae (Damm et al. 2012; Weir et al. 2012). It is thought that the incidence of this disease relates to the host plant (Weir et al. 2012). Ureña-Padilla et al. (2002) suggested that the $C$. gloeosporioides complex caused anthracnose in the root crown, that $C$. acutatum caused anthracnose in the fruit, and that the C. gloeosporioides complex caused the infection in the canopy. The $C$. gloeosporioides species complex most commonly causes strawberry anthracnose in China, whereas the $C$. acutatum species complex occasionally causes anthracnose (Xie et al. 2010). Three C. acutatum isolates were
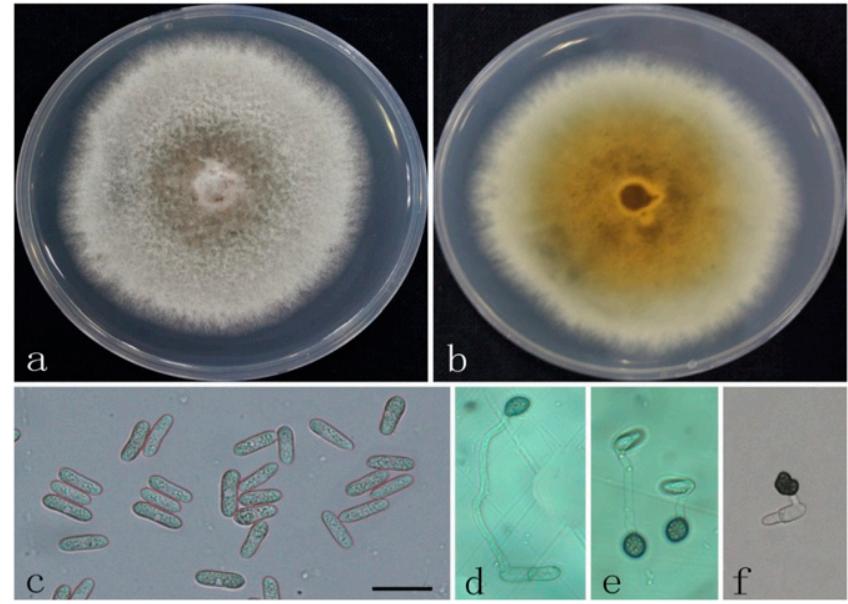

Fig. 5. Colletotrichum gloeosporioides. $\mathbf{a}$ and $\mathbf{b}$, Cultures of GT-10 on potato dextrose agar; $7-d$ growth from single conidia from above and below. c, Conidia. $d$ to $f$, Appressoria. Scale bar in $\mathbf{c}=20 \mu \mathrm{m}$ in $\mathbf{c}$ to $\mathbf{f}$.
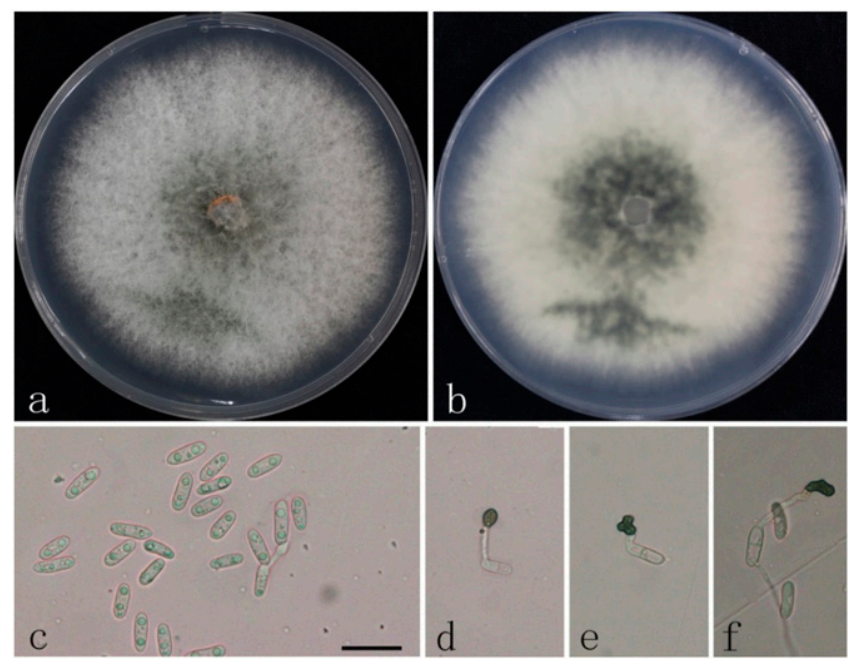

Fig. 6. Colletotrichum aenigma. a and $b$, Cultures of nbg-18 on potato dextrose agar 7-d growth from single conidia from above and below. $\mathbf{c}$, Conidia. $\mathbf{d}$ to f, Appressoria. Scale bar in $\mathbf{c}=20 \mu \mathrm{m}$ in $\mathbf{c}$ to $\mathbf{f}$. 
Table 2. Summary of morphological data of Colletotrichum isolates and pathogenicity of four group strains on stabbing and nonstabbing of strawberry leaves

\begin{tabular}{|c|c|c|c|c|c|c|c|c|c|c|}
\hline \multirow{3}{*}{$\begin{array}{l}\text { Species or } \\
\text { isolate no. }\end{array}$} & \multirow[b]{3}{*}{ Characteristics $^{\mathbf{v}}$} & \multirow{2}{*}{\multicolumn{2}{|c|}{ Conidia $^{w}$}} & \multirow{2}{*}{\multicolumn{2}{|c|}{ Appresoria $^{\text {w }}$}} & \multirow{3}{*}{$\begin{array}{c}\text { Growth } \\
\text { rate } \\
(\mathbf{m m} / \mathbf{d})^{\mathbf{x}}\end{array}$} & \multicolumn{2}{|c|}{ Wounded leaves $^{\mathbf{y}}$} & \multicolumn{2}{|c|}{ Nonwounded leaves ${ }^{y}$} \\
\hline & & & & & & & \multirow{2}{*}{$\begin{array}{c}\text { Disease } \\
\text { incidence }(\%)\end{array}$} & \multirow{2}{*}{$\begin{array}{c}\text { Lesion } \\
\text { diameter }^{z} \\
(\mathbf{m m})\end{array}$} & \multirow{2}{*}{$\begin{array}{c}\text { Disease } \\
\text { incidence (\%) }\end{array}$} & \multirow{2}{*}{$\begin{array}{c}\text { Lesion } \\
\text { diameter }^{\mathrm{Z}} \\
(\mathrm{mm})\end{array}$} \\
\hline & & Length $(\mu \mathrm{m})$ & Width ( $\mu \mathrm{m})$ & Length $(\mu \mathrm{m})$ & Width $(\mu \mathrm{m})$ & & & & & \\
\hline $\begin{array}{l}\text { Colletotrichum } \\
\text { fructicola }\end{array}$ & Off-white, with & $15.3 \pm 1.1(11.3-17.2)$ & $5.2 \pm 0.5(2.3-6.1)$ & $8.8 \pm 0.6(8.1-10.5)$ & $7.2 \pm 0.4(6.5-8.2)$ & $7.4 \pm 0.2$ & 79.9 a $(76.9-82.9)$ & $20.5 \mathrm{a}$ & 22.2 a $(19.2-25.2)$ & $17.0 \mathrm{a}$ \\
\hline $\begin{array}{l}\text { Colletotrichum } \\
\text { siamense }\end{array}$ & Off-white, with & $14.8 \pm 0.5(12.1-16.8)$ & $4.2 \pm 0.4(2.5-7.3)$ & $8.4 \pm 0.9(7.5-9.4)$ & $7.6 \pm 0.5(6.7-8.8)$ & $5.7 \pm 0.4$ & 88.9 a $(84.8-93.0)$ & $15.5 \mathrm{ab}$ & $6.3 \mathrm{~b}(2.7-9.9)$ & $1.0 \mathrm{~d}$ \\
\hline $\begin{array}{l}\text { Colletotrichum } \\
\text { gloeosporioides }\end{array}$ & Off-white, lacking & $13.4 \pm 0.7(12.8-15.3)$ & $4.3 \pm 0.4(2.1-6.5)$ & $7.1 \pm 0.4(6.6-8.3)$ & $5.4 \pm 0.6(5.1-6.4)$ & $7.7 \pm 0.3$ & 89.7 a $(82.9-96.6)$ & $13.5 \mathrm{~b}$ & $12.8 \mathrm{ab}(1.9-27.5)$ & $6.9 \mathrm{c}$ \\
\hline $\begin{array}{l}\text { Colletotrichum } \\
\text { aenigma }\end{array}$ & Off-white, lacking & $14.0 \pm 0.8(12.5-16.6)$ & $4.5 \pm 0.3(2.9-4.9)$ & $9.4 \pm 0.7(8.2-9.6)$ & $6.4 \pm 1.0(5.6-7.2)$ & $7.2 \pm 0.2$ & 81.5 a $(73.0-90.0)$ & $14.5 \mathrm{~b}$ & $14.8 \mathrm{ab}(6.8-22.8)$ & $11.7 \mathrm{~b}$ \\
\hline
\end{tabular}

u All of the 91 isolates were assessed.

$v$ Colony characteristics: off-white, lacking, off-white mycelia lacking conidial masses; off-white, with, off-white mycelia with mass conidial masses.

w Data are mean \pm standard deviation or standard error, with ranges in parentheses.

$\mathrm{x}$ Data are mean \pm standard deviation or standard error.

y Disease was assessed 7 days after inoculation with conidial suspension of Colletotrichum spp. by spray.

$\mathrm{z}$ Data are mean \pm standard deviation. Mean values with the same letters were not statistically different $(P>0.05)$ according to the least significant difference test

identified in Hubei, China, by Han et al. (2016). This study did not found any $C$. acutatum species that have previously been reported to cause strawberry plant infections (MacKenzie et al. 2008).

\section{Acknowledgments}

We thank LetPub (https://www.letpub.com/) for its linguistic assistance during the preparation of this manuscript.

\section{Literature Cited}

Afanador-Kafuri, L., Minz, D., Maymon, M., and Freeman, S. 2003. Characterization of, Colletotrichum isolates from tamarillo, passiflora, and mango in Colombia and identification of a unique species from the genus. Phytopathology 93:579-587.

Buddie, A. G., Martínez-Culebras, P., Bridge, P. D., García, M. D., Querol, A., Cannon, P. F., and Monte, E. 1999. Molecular characterization of Colletotrichum isolates derived from strawberry. Mycol. Res. 103:385-394.

Cai, L., Hyde, K. D., Taylor, P., Weir, B. S., Waller, J. M., Abang, M. M., Zhang, J. Z., Yang, Y. L., Phoulivong, S., Liu, Z. Y., Prihastuti, H., Shivas, R. G., McKenzie, E. H. C., and Johnston, P. R. 2009. A polyphasic approach for studying Colletotrichum. Fungal Divers. 39:183-204.

Cannon, P. F., Buddie, A. G., and Bridge, P. D. 2008. The typification of Colletotrichum gloeosporioides. Mycotaxon 104:189-204.

Cannon, P. F., Damm, U., Johnston, P. R., and Weir, B. S. 2012. Colletotrichum — current status and future directions. Stud. Mycol. 73:181-213.

Carbone, I., and Kohn, L. M. 1999. A method for designing primer sets for speciation studies in filamentous ascomycetes. Mycologia 91:553-556.

Damm, U., Cannon, P. F., Woudenberg, J. H. C., and Crous, P. W. 2012. The Colletotrichum acutatum species complex. Stud. Mycol. 73:37-113.

de los Santos García de Paredes, B., and Romero Muñoz, F. 2002. Effect of different fungicides in the control of Colletotrichum acutatum, causal agent of anthracnose crown rot in strawberry plants. Crop Prot. 21:11-15.

Dean, R., Van Kan, J. A., Pretorius, Z. A., Hammond-Kosack, K. E., Di Pietro, A., Spanu, P. D., and Foster, G. D. 2012. The top 10 fungal pathogens in molecular plant pathology. Mol. Plant Pathol. 13:414-430.

Debode, J., Hemelrijck, W., Baeyen, S., Creemers, P., Heungens, K., and Maes, M. 2009. Quantitative detection and monitoring of Colletotrichum acutatum in strawberry leaves using real-time PCR. Plant Pathol. 58:504-514.

Denoyes-Rothan, B., Guérin, G., Délye, C., Smith, B., Minz, D., and Maymon, M. 2003. Genetic diversity and pathogenic variability among isolates of Colletotrichum species from strawberry. Phytopathology 93:219-228.

Freeman, S., and Katan, T. 1997. Identification of Colletotrichum species responsible for anthracnose and root necrosis of strawberry in Israel. Phytopathology 87:516-521.

Freeman, S., Katan, T., and Shabi, E. 1998. Characterization of Colletotrichum species responsible for anthracnose disease of various fruits. Plant Dis. 82: 596-605.

Gardes, M., and Bruns, T. D. 1993. ITS primers with enhanced specificity for basidiomycetes - application to the identification of mycorrhizae and rusts. Mol. Ecol. 2:113-118

Han, Y. C., Zeng, X. G., and Xiang, F. Y. 2016. Distribution and characteristics of Colletotrichum spp. associated with anthracnose of strawberry in Hubei, China. Plant Dis. 100:996-1006.

He, Y., Fan, G. F., Zhang, X. W., Li, Z. Q., and Gao, D. W. 2013. Vegetation phenological variation and its response to climate changes in Zhejiang province. J. Nat. Resour. 28:220-233.

Henz, G. P., Boiteux, L. S., and Lopes, C. A. 1992. Outbreak of strawberry anthracnose caused by Colletotrichum acutatum in central Brazil. Plant Dis. 76:212.

Hu, D. Y., Qian, C., and Liu, X. F. 2014. Research progress of strawberry anthracnose. Chin. Vegetables 1:9-14.
Hyde, K. D., Nilsson, R. H., Alias, S. A., Ariyawansa, H. A., Blair, J. E., Cai, L., de Cock, A. W. A. M., Dissanayake, A. H., Glockling, S. L., Goonasekara, I. D., Gorczak, M., Hahn, M., Jayawardena, R. S., van Kan, J. A. L., Laurence, M. H., Lévesque, C. A., Li, X. H., Liu, J. K., Maharachchikumbura, S. S. N., Manamgoda, D. S., Martin, F. N., McKenzie, E. H. C., McTaggart, A. R., Mortimer, P. E., Nair, P. V. R., Pawłowska, J., Rintoul, T. L., Shivas, R. G., Spies, C. F. J., Summerell, B. A., Taylor, P. W. J., Terhem, R. B., Udayanga, D., Vaghefi, N., Walther, G., Wilk, M., Wrzosek, M., Xu, J.-C., Yan, J., and Zhou, N. 2014. One stop shop: Backbones trees for important phytopathogenic genera: I 2014. Fungal Divers. 67:21-125.

Larkin, M. A., Blackshields, G., Brown, N. P., Chenna, R., and McGettigan, P. A. 2007. Clustal W and Clustal X version 2.0. Bioinformatics 23: 2947-2948.

Lee, D. H., Kim, D. H., Jeon, Y. A., Uhm, J. Y., and Hong, S. B. 2007. Molecular and cultural characterization of Colletotrichum spp. causing bitter rot of apples in Korea. Plant Pathol. J. 23:37-44.

Li, N. 2012. Study on pathogen species and population genetic diversity of anthracnose. Sichuan Agricultural University, Chengdu, China.

MacKenzie, S. J., Mertely, J. C., Seijo, T. E., and Peres, N. A. 2008 Colletotrichum fragariae is a pathogen on hosts other than strawberry. Plant Dis. 92:1432-1438.

Mertely, J. C., and Legard, D. E. 2004. Detection, isolation, and pathogenicity of Colletotrichum spp. from strawberry petioles. Chem. Monthly 139: 1457-1461.

Mongkolporn, O., and Taylor, P. W. J. 2018. Chili anthracnose: Colletotrichum taxonomy and pathogenicity. Plant Pathol. 67:1255-1263.

Nylander, J. A. A. 2004. MrModeltest v2. Evolutionary Biology Centre, Uppsala University, Uppsala, Sweden.

Page, R. D. 1996. TreeView: An application to display phylogenetic trees on personal computers. Comput. Appl. Biosci. 12:357-358.

Peng, D. L., and Peng, S. L. 2011. Strawberry biological characteristics and key cultivation techniques. Jilin Vegetables 5:22-24.

Peng, L. J., Sun, T., Yang, Y. L., Cai, L., Hyde, K. D., and Bahkali, A. H. 2013. Colletotrichum species on grape in Guizhou and Yunnan provinces, China. Mycoscience 54:29-41.

Peres, N. A., MacKenzie, S. J., Peever, T. L., and Timmer, L. W. 2008. Postbloom fruit drop of citrus and Key lime anthracnose are caused by distinct populations of Colletotrichum acutatum. Phytopathology 98:345-352.

Phoulivong, S., Cai, L., Chen, H., Mckenzie, E. H. C., Abdelsalam, K., and Chukeatirote, E. 2010. Colletotrichum gloeosporioides is not a common pathogen on tropical fruits. Fungal Divers. 44:33-43.

Polashock, J. J., Caruso, F. L., Oudemans, P. V., McManus, P. S., and Crouch, J. A. 2009. The North American cranberry fruit rot fungal community: a systematic overview using morphological and phylogenetic affinities. Plant Pathol. 58:1116-1127.

Prihastuti, H., Mckenzie, E. H. C., Hyde, K. D., Cai, L., and Hyde, E. H. C. A. 2009. Characterization of Colletotrichum species associated with coffee berries in northern Thailand. Fungal Divers. 39:89-109.

Rojas, E. I., Rehner, S. A., Samuels, G. J., Bael, S. A. V., Herre, E. A., and Cannon, P. 2010. Colletotrichum gloeosporioides s.l. associated with theobroma cacao and other plants in panamá: Multilocus phylogenies distinguish hostassociated pathogens from asymptomatic endophytes. Mycologia 102: $1318-1338$.

Ronquist, F., and Huelsenbeck, J. P. 2003. Mrbayes 3: Bayesian phylogenetic inference under mixed models. Bioinformatics 19:1572-1574.

Sangeetha, C. G., and Rawal, R. D. 2007. Nutritional studies of Colletotrichum gloeosporioides (penz.)penz. and sacc. the incitant of mango anthracnose. American-Eurasian J. Sustain. Agric. 4:37-41.

Shen, H. R. 2014. Analysis of the role of agricultural technology in the development of strawberry industry in Jiande City and its development countermeasures. Zhejiang University, Hangzhou, China. 
Talhinhas, P., Mota-Capitão, C., Martins, S., Ramos, A. P., Neves-Martins, J., Guerra-Guimarães, L., Várzea, V., Silva, M. C., Sreenivasaprasad, S., and Oliveira, H. 2011. Epidemiology, histopathology and aetiology of olive anthracnose caused by Colletotrichum acutatum and C. gloeosporioides in Portugal. Plant Pathol. 60: 483-495.

Tamura, K., Peterson, D., Peterson, N., Stecher, G., and Nei, M. 2011. MEGA 5: Molecular evolutionary genetics analysis using maximum likelihood, evolutionary distance, and maximum parsimony methods. Mol. Biol. Evol. 28:2731-2739.

Templeton, M. D., Rikkerink, E. H. A., Solon, S. L., and Crowhurst, R. N. 1992. Cloning and molecular characterization of the glyceraldehyde-3-phosphate dehydrogenase encoding gene and cDNA from the plant pathogenic fungus Glomerella cingulata. Gene 122:225-230.

Udayanga, D., Manamgoda, D. S., and Xingzhong, L. 2013. What are the common anthracnose pathogens of tropical fruits? Fungal Divers. 61:165-179.

Ureña-Padilla, A. R., Mackenzie, S. J., Bowen, B. W., and Legard, D. E. 2002. Etiology and population genetics of Colletotrichum spp. causing crown and fruit rot of strawberry. Phytopathology 92:1245-1252.

Vaidya, G., Lohman, D. J., and Meier, R. 2011. Sequence matrix: Concatenation software for the fast assembly of multi-gene datasets with character set and codon information. Cladistics Int. J. Willi Hennig Soc. 27:171-180.
Wang, F., Ma, Y., Gao, X. Y., and Zhang, Z. H. 2008. Study on the identification techniques for determining strawberry cultivars resistance to anthracnose. $\mathrm{J}$. Fruit Sci. 25:542-547.

Weir, B. S., Johnston, P. R., and Damm, U. 2012. The Colletotrichum gloeosporioides species complex. Stud. Mycol. 73:115-180.

Wharton, P. S., and Schilder, A. M. C. 2008. Novel infection strategies of Colletotrichum acutatum on ripe blueberry fruit. Plant Pathol. 57:122-134.

White, T. J., Bruns, T., Lee, S., and Taylor, J. W. 1990. Amplification and direct sequencing of fungal ribosomal RNA genes for phylogenetics. Pages 315-322 in: PCR Protocols: A Guide to Methods and Applications. M. A. Innis, D. H. Gelfand, J. J. Sninsky, and T. J. White, eds. Academic Press, San Diego, CA.

Wikee, S., Cai, L., Pairin, N., Mckenzie, E. H. C., Su, Y. Y., and Chukeatirote, E. 2011. Colletotrichum species from jasmine (Jasminum sambac). Fungal Divers. 46:171-182.

Xie, L., Zhang, J. Z., Wan, Y., and Hu, D. W. 2010. Identification of Colletotrichum, spp. isolated from strawberry in Zhejiang province and Shanghai city, China. J. Zhejiang Univ. Sci. B 11:61-70.

Yan, J., Wu, P. S., Du, H. Z., and Zhang, Q. E. 2011. First report of black spot caused by Colletotrichum gloeosporioides on paper mulberry in China. Plant Dis. 95:880. 